IOSR Journal of Pharmacy

ISSN: 2250-3013, www.iosrphr.org

||| Volume 2 Issue 5 ||| Sep-Oct. 2012 || || PP.44-46

\title{
Antibiotic resistance pattern of mdr pathogens
}

\author{
Priti Vyas \\ Dept. of Biotechnology, P.M.B. Gujarati Science College, Indore
}

\begin{abstract}
Multiple drug resistant enterobacterial pathogens were isolated from common sources of human consumption. The isolates were subjected for antibiotic susceptibility testing against 10 antibiotics and found to be resistant towards six antibiotics. All the isolated MDR pathogens were found to be sensitive towards amikacin. Sensitivity for cefuroxime, oxacillin, and metronidazol differed for different species. The pattern of MDR bacteria was perturbing as simultaneous resistance to chloramphenicol and gentamycin, formed the common MDR pattern. The pattern was almost the same for the diverse species (Escherichia coli, Klebsiella pneumoniae, Citrobacter diversus, Shigella flexneri, Salmonella typhi, Proteus vulgaris, Citrobacter freundii, Proteus myxofaciens, Klebsiella oxytoca, and Pseudomonas aeruginosa) isolated from different food samples and strongly suggests prevalence of similar $R$ plasmids. This suggests that antibiotic resistance is encoded on a high molecular weight plasmid, and can easily spread in the community through food stuff generally consumed by the common man.
\end{abstract}

Keywords-MDR, antibiotics, enterobacterial pathogens.

\section{INTRODUCTION}

Very large number of publications appeared in the literature concerning the development of drug resistance in a variety of microbes present in food items, fruit juices, sweets, sprouts, milk and milk products, fresh and marine waters. The fear of transfer of multidrug resistance to pathogens like Salmonella typhi came true in 1972 resulting in an epidemic of chloramphenicol resistant S. typhi and in 1992 another epidemic with simultaneous resistance for chloramphenicol, co-trimoxazole and ampicillin (Chitnis et al., 2000). Salmonella $s p$. is responsible for an estimated 0.8 to 4.0 million infections in the United States each year usually taking the form of gastroenteritis following the consumption of contaminated food. The incidence of resistant bacteria in foodstuff is a worldwide phenomenon. It is a major public health threat (Rahman and Malik, 2001).

The occurrence of transferable drug resistance mediated by plasmids, called $\mathrm{R}$ factor, has been extensively documented since it was first observed in Japan in 1959. Mandal et al. (2004) investigated the occurrence of R-plasmids among MDR isolates of Escherichia coli, Proteus vulgaris and Klebsiella pneumoniae from different clinical cases isolated from in and around Calcutta, India. The multidrug resistant $S$. typhi strains contained a transferable plasmid conferring resistance to ampicillin, chloramphenicol, cotrimoxazole and tetracycline. The spread of antibiotic resistance among pathogenic bacteria thus posed a serious problem of therapeutic failure during the treatment of infectious diseases. The adaptation to antibiotics present in the aqueous environment is due to acquisition and dissemination of simple antibiotic resistance genes by mobile genetic elements (Cruz and Davies, 2000). As described by Gaynes and Monnet (1997), some contributing factors include cross transmission, inter hospital resistance transfer, a community contribution to resistance and the use of a variety of antibiotics.

The present study aims at isolation and characterization of MDR enterobacterial pathogens from various food samples. These samples are consumed by the common man in India, thru which infection could occur which could be difficult to cure due to their multiple drug resistant nature.

\section{MATERIALS AND METHODS}

Ten MDR pathogens were isolated from various sources including food items consumed by the common man. All organisms were isolated on chloremphenicol and gentamycin supplemented MacConkey agar and identified as members of Enterobacteriacae. Antibiotic susceptibility testing was conducted on MullerHinton agar using disc diffusion method described by Bauer et al. (1966) using commercial antibiotic discs purchased from Hi-media Laboratories. The discs were placed on Muller-Hinton agar previously seeded with $0.5 \mathrm{ml}$ test culture grown for $24 \mathrm{~h}$. The antibiotics used were Nalidixic acid, Gentamycin, Chloramphenicol, Metronidazole, Ciprofloxacin, Amikacin, Norfloxacin, Oxacillin, Cefuroxime and Ampicillin. The antibiotic resistance pattern was recorded after incubation of plates at $37 \mathrm{o} \mathrm{C}$ for $48 \mathrm{~h}$. 


\section{RESULTS AND DISCUSSION}

Table 1 demonstrates the antibiotic resistant phenotypes of MDR pathogens used in the study. The organisms were found to be resistant towards almost all the antibiotics. All the isolated MDR pathogens were found to be sensitive towards amikacin. Sensitivity for cefuroxime, oxacillin, and metronidazol differed for different species.

\begin{tabular}{|c|c|c|}
\hline Genus and species & Sensitivity pattern & Resistance phenotypes \\
\hline Escherichia coli & Ami & Cip, N A, Amp, Cef, Oxa, Met, Gen, Chl, Nor \\
\hline Klebsiella pneumoniae & Ami, Cef, Oxa & Cip, N A, Amp, Met, Gen, Chl, Nor \\
\hline $\begin{array}{l}\text { Pseudomonas } \\
\text { aeruginosa }\end{array}$ & Ami & Cip, N A, Amp, Cef, Oxa, Met, Gen, Chl, Nor \\
\hline Citrobacter diversus & Ami & Cip, N A, Amp, Cef, Oxa, Met, Gen, Chl, Nor \\
\hline Shigella flexneri & Ami & Cip, N A, Amp, Cef, Oxa, Met, Gen, Chl, Nor \\
\hline Klebsiella oxytoca & Ami , Cef & Cip, N A, Amp, Oxa ,Met, Gen, Chl, Nor \\
\hline Salmonella typhi & Ami, Cef & Cip, N A, Amp, Oxa, Met, Gen, Chl, Nor \\
\hline Proteus vulgaris & Ami & Cip, N A, Amp, Cef, Oxa, Met, Gen, Chl, Nor \\
\hline Citrobacter freundii & Ami, Cef & Cip, N A, Amp, Oxa, Met, Gen, Chl, Nor \\
\hline Proteus myxofaciens & Ami, Oxa, Met & Cip, Cef, N A, Amp, Gen, Chl, Nor \\
\hline \multicolumn{3}{|c|}{$\begin{array}{l}\text { Ami - Amikacin, N A- Nalidixic acid, Cef - Cefuroxime, Amp- Ampicillin, Oxa - Oxacillin, } \\
\text { Met - Metronidazol, Gen - Gentamycin, Chl - Chloramphenicol, Cip - Ciprofloxacin, Nor - } \\
\text { Norfloxacin.Conc. of each antibiotic }=10 \mu \mathrm{g} / \text { disc. }\end{array}$} \\
\hline
\end{tabular}

Maximum number of isolates was found to be associated with the swabbing of tea glasses and plates, and found to contain Escherichia coli, Klebsiella pneumoniae, Citrobacter diversus and Proteus vulgaris. The next major source of MDR pathogens was water sprinkled on vegetables by vegetable vendors and found to contain Escherichia coli, Citrobacter diversus, Shigella flexneri, Citrobacter freundii, Klebsiella oxytoca and Pseudomonas aeruginosa.

In the aqueous environment, the transfer of resistance factor within and between the bacterial genera has been shown by Grabow and Prozesky (1973) using Escherichia coli resistant to ampicillin, chloramphenicol, sulfonamide and tetracycline. The MDR isolates collected during the present study indicated the presence of plasmids of almost identical size of approximate $60 \mathrm{~kb}$, however an opportunistic pathogen Pseudomonas aeruginosa contained a plasmid of slightly higher molecular weight.

The pattern of MDR bacteria was perturbing as simultaneous resistance to chloramphenicol and gentamycin, formed the common MDR pattern. The pattern was almost the same for the diverse species (Escherichia coli, Klebsiella pneumoniae, Citrobacter diversus, Shigella flexneri, Salmonella typhi, Proteus vulgaris, Citrobacter freundii, Proteus myxofaciens, Klebsiella oxytoca, and Pseudomonos aeruginosa) and strongly suggests prevalence of similar R plasmids. These results can be co-related with the antibiotic patterns of the isolates. Almost similar antibiotic resistance pattern was observed for all isolates. These results suggest that antibiotic resistance is encoded on a high molecular weight plasmid as also suggested by Chitnis et al., (2000). They reported similar MDR pattern in diverse species and presence of similar plasmid DNA bands on gel electrophoresis and demonstrated the presence of high molecular weight $\mathrm{R}$ plasmids (>10 $\mathrm{kb}$ ) in MDR isolates obtained from hospital effluents. The present study confirms that the antibiotic resistance is encoded on a high molecular weight plasmid, and can easily spread in the community thru food stuff generally consumed by the common man. 


\section{REFERENCES}

[1]. Bauer AW, Kirby WM, Sherris JC, Turek. 1966. Antibiotic susceptibility testing by a standardised single disk method. American Journal of Clinical Pathology. 45, 493.

[2]. Chitnis V, Chitnis D, Patil S, Ravikant 2000. Hospital effluent- A source of multiple drug resistant bacteria. Current Science 79, 989.

[3]. Cruz F, Davies J, 2000. Horizontal gene transfer and the origin of species: lessons from bacteria. Trends in Microbiology. 8,128.

[4]. Gaynes R, Monnet, D. 1997. The contribution of antibiotic use on the frequency of antibiotic resistance in hospitals. Ciba. Foundation Symposium. 207, 47.

[5]. Grabow WOK, Prozesky OW. 1973. Drug resistance of coliform bacteria in hospital and city sewage. Antimicrobial agents and Chemotherapy. 3, 175.

[6]. Kado C, Liu S. 1981. Rapid Procedure for Detection and Isolation of Large and Small Plasmids. Journal of Bacteriology. 145, 1365.

[7]. Rahman K, Malik A. 2001. Antibiotic resistance and detection of $\beta$ - lactamase in bacterial strains of Staphylococci and Escherichia coli isolated from foodstuffs. World Journal of Microbial Biotechnology. 17, 863.

[8]. Sambrook J, Fritsch E, Maniatis T. 1989. Molecular cloning : A laboratory Mannual, 2nd ed. Cold Spring Harbor, N Y, USA. Cold spring Harbour Laboratory Press. 